\title{
Study on factors influencing employee retention in companies
}

\author{
Harpreet Kaur Rakhra \\ Jagannath Institute of Management Sciences, \\ Sec-3, Rohini, 85, Delhi, India \\ Email: harpreetkr@gmail.com
}

\begin{abstract}
Employee retention refers to the ability of the organisation to retain its employees. Great businesses value dedicated workers and know how to retain them. An organisation spends huge amount of money on hiring people and training them still every year many businesses suffer from a huge loss of talent. The paper includes a survey in which 220 employees are questioned on job satisfaction. The sample includes randomly selected employees from different companies located in Delhi/NCR. The study concluded that almost all the employees felt that the company is not doing enough to retain them and they have plans to change the job if it continues. There are many ways a company suffers because of employees. The paper presents potential reasons that may compel an employee to leave a job and also the strategies that can help organisation retain its top performers.
\end{abstract}

Keywords: employee retention; staff turnover; job satisfaction; retention strategies.

Reference to this paper should be made as follows: Rakhra, H.K. (2018) 'Study on factors influencing employee retention in companies', Int. J. Public Sector Performance Management, Vol. 4, No. 1, pp.57-79.

Biographical notes: Harpreet Kaur Rakhra hails from an army background. She graduated (Eng Hons.) from Delhi University in 1999. She obtained her MA in English Literature in 2001 and MBA in 2015. She is currently pursuing MA in Psychology from IGNOU. She is a highly experienced professional having 17 years of rich work experience. She has been working as an Assistant Professor for subjects like Business Communication and HR at Jagannath Institute of Management Sciences for more than seven years. She has worked with several well known language training schools in Delhi and has also worked as a content developer in Educomp Learning Private Ltd.

\section{Introduction}

A place is called an organisation where individuals work together in unison towards common goals. An organisation cannot survive for long if the employees working in it are not serious about the goals and mission vision of the organisation. Today employee retention is the top priority of organisations due to increasing competition. There are infinite reasons for an employee to leave the job including finding a different job, shifting to a different place, getting angry about something and deciding to quit, women getting married, entering motherhood and so on. When an employee leaves he also takes the 
skills that he learnt during his tenure with the company. The employee may get another similar or better job but it is hard for the company to find a similarly suitable employee for the post that he left vacant. The companies need to understand the importance of employee retention for various reasons. Sincere efforts should be made towards retaining the employees so that they do not look for a change or are compelled to leave the job. Staff turnover however can also be an indication of not selecting the candidates carefully at the time of recruitment.

One of the most important concerns for an organisation today is employee retention. Employees have a tendency to move to the other organisation for better opportunities despite being trained so well in the current organisation. Individuals move to other organisation for various reasons including better salary, better growth prospects and better ambience among others. If a trained and efficient employee wants to change the job it becomes very important for the HR team to understand the reasons. The HR team of many successful organisations plan strategies for retaining the top performers. There is a strong need to understand the following reasons behind the retention strategies.

- A lot of time and money is invested by the organisation on hiring the employee: to understand the importance of employee retention it is important to first understand that the company spends huge amount of money and time on hiring the employee and also on his grooming so high turnover proves to be expensive for the company. (Merhar, 2016) These days every organisation expects the employee to be good not only in his technical but also in the soft skills which are crucial for an employee and later for the company's success. For this there are several interview rounds and several panel of evaluators involved in the process, all this requires quite a lot of time and money. The interview rounds take several days and in some cases several months also. But these carefully chosen employees eventually become the reason for the success of the company and the satisfaction of the clients.

- Retention boosts the organisation's productivity: it is understood that hiring and training the new employees takes time thus if the experienced and efficient employees are retained the productivity of the company will automatically be improved. If there is an unfilled position it would definitely hamper the work. It might affect the morale of the employees around as well (Siddiqui, 2015). The performance of the organisation depends on the productivity of the employee thus the HR team should try every possible way to keep the present employees satisfied with their job so that they do not think of leaving because no organisation can perform if the top talent quits.

- Retention increases unity among the staff members: the more time the employees spend with one another the more familiar they become (Edwards, 2015). Since they interact with each other during work hours, they feel united and are able to relate to the company's vision and mission also. This helps the organisation immensely as the employees work seriously towards the goals of the company. It is also seen that these employees perform better than the employees who change jobs frequently. 
- The best talent may go to the competitor: when an employee leaves the job he is most likely to join a competitor which is not good for the organisation (Son, 2016). Every employee wants to impress his employers with good suggestions for the company's betterment. There are chances that the good policies and strategies of the company are taken to the other company by the employee helping them to grow. Thus the company loses not only a good employee but also its good market position.

The present study focuses on the reasons behind the employee attrition apart from discussing the importance of employee retention. The study emphasises on employee retention, as an organisation cannot think of long term success if there is a problem of staff turnover. The study aims to find out the reasons behind employee turnover on the basis of gender, age and the organisation level of the employee. Introduction is followed with the literature review of the employee retention researches conducted. This is followed by objectives and research methodology. Then the next section focuses on data analysis followed with implication and conclusion of the study.

\section{Literature review}

Various studies have been considered in order to assess the reasons behind employees leaving the organisation. The present covers the literature from the year 2000-2016.

Dana (2000) attempted to study the history of entrepreneurship in India. It was concluded that India is a culturally-diverse country with very large population. This population could produce great entrepreneurs. Some organisations were already working hard at this. They were flourishing the confidence of the people and providing them the necessary resources. These resources could help the entrepreneurs to become successful.

Ramlall (2004) attempted to understand how the employee retention practices can be explained to the employees through the motivation theories. It was concluded in the study that in most cases the widely used practices of employee retention were developed and implemented without understanding the theory that explained the practice and why it might be effective. The employee retention was most important in case of talented workers.

Samuel and Chipunza (2009) conducted a study to find out reasons that influenced retention in an organisation. It was observed that intrinsic motivational variables significantly influenced retention amongst employees in both public and private sector organisations they included training and development; sense of belonging to the organisation; job security; challenging/interesting work; and freedom for innovative thinking.

Irshad (2011) attempted to identify the elements of HR practices and their effect on employee retention in a given organisation. It was observed that HR practices did have a very strong influence on employee retention in any organisation. Compensation, rewards, flexi timings, trainings and promotion opportunities were also important factors among others. 
Kyndt et al. (2011) conducted a study to investigate the factors that have an influence on employee retention. It was discovered that the organisations should give learning opportunities to the employees for their better retention. The employees could be retained if the organisation allowed them to learn what they are good at.

Sageer et al. (2012) attempted to study the variables that kept the employee motivated at the workplace. It was emphasised that successful organisations formulated strategies that made the work environment strong, boost the employee morale and employee satisfaction. This in turn enhanced employee performance and his productivity. All this eventually lead to high profits, customer satisfaction and most importantly employee retention.

Sinha and Sinha (2012) made an attempt to find out why certain people stayed in a company for longer. Findings revealed that there were different reasons behind each employee willing to continue the job in the same company. There were different things appealing to an employee in one organisation. The same factors in other organisations were not appealing to its employees.

Mohlala et al. (2012) conducted a study to understand the challenges faced by the management to retain employees. The findings indicated that the lack of a strong retention strategy within the organisation was a reason for employee turnover. Further the organisation was not being able to provide more conducive environment to the employees and not paying attention to the demands of a certain group of the employees.

Nazia and Begum (2013) aimed to formulate the rules of retention in the organisation and found out that retention consists of 3 R's: respect, recognition and rewards which helped in retaining effective employees. To keep effective employees and keep satisfaction high, the company needed to implement each of the three Rs of employee retention. It was emphasised that organisations should take steps to relieve the employees from the workload through job rotation; they could bring change in the work location and introduce some recreational activities for employees. It was also believed that implementation of three R's would increase staff retention.

Savarimuthu and Hemalatha (2013) focused their study on assessing the level of satisfaction of the overall employee retention techniques. It was found out that the majority of the respondents appreciated the retention strategy measures adopted by the company. It was emphasised that retaining a qualified and motivated employee was extremely important.

Das and Baruah (2013) attempted to explore the relation between certain factors and job satisfaction. It was concluded that factors like compensation, rewards and recognition, opportunities for promotion and growth, work life balance a job security were some factors among others that affected an employee's retention in an organisation. It was emphasised that if these factors existed in the organisation the employee does not think of leaving the job.

Bagga (2013) aimed his study at finding reasons behind the high attrition rates of employees. It was found that if an employee stayed longer in a company he was less likely to leave the organisation. If the employees were made to feel valued they, kept informed and promised a clear growth path they could easily be retained.

Dutta and Banerjee (2014) tried to focus on knowing the potential reasons for an employee to leave his job. Also the problems faced by the organisation because of high staff turnover. It was observed that lack of trainings, career development opportunities and no recognition of skills lead to the staff attrition. The authors observed that because 
of lack of open communication among the staff members and with the management there were problems in the smooth functioning of the business.

Mehta et al. (2014) attempted to know the practices that kept the staff motivated and retained. The observations said that there were no fixed practices that show the relevance and significance as to how to retain employees and keep them committed towards the organisation because employers laid different emphasis on different variables depending on what suited their organisation best. Hiring employees was just the beginning to creating a strong committed work force. The real task was to retain them. Through employee retention businesses maintained an effective workforce and at the same time met operational requirements. A lot of employee related issues like salary, benefits administration, organisation development, motivation, benefits, communication, performance management and training were dealt by it.

Shakeel and Butt (2015) focused their study on finding out the factors that an employee considered important for his retention in the organisation and to find out the integrated set of variables that affected his retention. Study observed that there were not just financial factors but also non-financial factors like job content, trainings, work conditions and flexible work hours that mattered for an employee when it came to retention.

Satpal and Dhillon (2016) conducted a study to find out different retention strategies adopted by IT industry. It was observed that most companies realised the importance of employee retention. They gave lucrative salary, flexible timings, better work environment and career growth prospects. They were willing to make changes in their retention strategies for a talented and productive employee.

Kossivi et al. (2016) aimed at determining the variables affecting employee turnover. The results showed there was a need to pay more heed to factors like organisation culture, training and development and autonomy. There were three categories that the workforce was divided into: directors, managers and employees. Out of all three the least research work was done on the employees. They played a crucial role in the success of the business and hence were the most important asset for the organisation.

\section{Objectives}

1 To ascertain the reason behind employee turnover on the basis of the gender.

2 To identify whether employee's age plays any role in employee turnover in a company.

3 To analyse if the organisation level plays any role behind employee's resignation.

\section{Research methodology}

Descriptive design is selected for the present study. This will highlight the causes of employee turnover with further subdivision on the basis of gender, people working on different organisation levels and age groups. The sample of the research is various companies located in Delhi-NCR. 
A questionnaire survey method was used to gather data for the present study. A questionnaire was used as an instrument for the purpose of data collection. For such study a questionnaire was thought to be the most appropriate tool. 300 questionnaires were distributed via email and in physical form, out of which 250 were filled and came back, after filtration of questionnaires 220 were selected, which were used for the final evaluation and analysis.

The first seven questions have gathered the background information about the respondents. The questions gather information on age, gender and hierarchical positions, length of service in the present organisation and marital status among others. From question 8 to 13 , there are questions related to various other factors important for retention. The statements are directed towards various reasons behind the employee satisfaction that leads to the retention. Question 14 indicates the response of employees on training opportunities. The last question of the questionnaire is an open ended question that seeks the suggestion of the employees on retention strategies.

Factor analysis has been used to analyse the factors responsible for employee retention in companies. Factor analysis is a statistical technique that reduces data and allows simplification of the co-relational relationships between continuous variables. Exploratory factor analysis is used to identify constructs and further investigate relationships between key interval scaled questions to ascertain reasons for staff turnover from a sample of 220 respondents of various companies. To test, following steps were taken:

1 At the first stage correlation matrices were computed. It proposed to go ahead with factor analysis as there is enough correlation.

2 A study of Kaiser-Meyer-Olkin's measure of sampling adequacy (MSA) found enough correlation for all the variables.

3 Kaiser-Meyer-Olkin MSA's score of 0.783 indicated that the sample size was adequate for sampling.

4 Barlett test of sphericity was used to test the overall significance of correlation matrices and it also provided support for the validity of the factor analysis.

5 Once it was concluded that the data was suitable for factor analysis, data was extracted using principal components analysis that helped determine the factor underlying the relationship between variables.

\section{Analysis}

Analysis is structured in four sections. First sections highlights the KMO and Barlett's results, followed with the overall factors in relation to employee retention in companies. Second section proceeds with the factor analysis based on the gender, followed by factors on the basis of age groups and finally on the basis of organisational level.

At first KMO and Bartlett's test were conducted to ensure adequacy and significance of the sample. Since the KMO score is 0.783 (Table 1) and Bartlett's test is significant, thus the sample was adequate to run the factor analysis and decode the factors for employee retention. 
Table 1 KMO and Bartlett's test result

\begin{tabular}{ll}
\hline Kaiser-Meyer-Olkin measure of sampling adequacy & 0.783 \\
Bartlett's test of sphericity & 0.000 \\
\hline
\end{tabular}
Source: Author calculation

Table 2 Results of factor analysis

\begin{tabular}{|c|c|c|c|c|c|c|}
\hline Statements & 1 & 2 & 3 & 4 & 5 & 6 \\
\hline - Communication with the staff is easy & .937 & & & & & \\
\hline - Employee concerns are seriously considered & .778 & & & & & \\
\hline $\begin{array}{l}\text { - The suggestions given by employees are } \\
\text { considered }\end{array}$ & .746 & & & & & \\
\hline - The management decisions are unbiased & .683 & & & & & \\
\hline $\begin{array}{l}\text { - There are activities done to help employees } \\
\text { de-stress }\end{array}$ & .570 & & & & & \\
\hline $\begin{array}{l}\text { - I have great working relationship with my } \\
\text { colleagues }\end{array}$ & .562 & & & & & \\
\hline - Salary breakup is satisfactory & .494 & & & & & \\
\hline - Learning and development opportunities & & .850 & & & & \\
\hline - Help in career progression & & .725 & & & & \\
\hline - Reward and other benefits & & .724 & & & & \\
\hline - Working conditions & & .710 & & & & \\
\hline - Freedom while working & & .670 & & & & \\
\hline - Yearly bonus is given in time & & & .839 & & & \\
\hline - Appraisal system is fair and unbiased & & & .779 & & & \\
\hline - Extra payment is given for overtime & & & .543 & & & \\
\hline - Performance based incentives are given & & & .437 & & & \\
\hline - Career development & & & & .861 & & \\
\hline - Work culture & & & & .803 & & \\
\hline - Salary & & & & .634 & & \\
\hline - I am emotionally attached to my company & & & & .535 & & \\
\hline - Company's image & & & & .489 & & \\
\hline - Food is offered on subsidized rates & & & & & .878 & \\
\hline - First aid box is available all the time & & & & & .767 & \\
\hline $\begin{array}{l}\text { - Lunch breaks and other breaks are given } \\
\text { appropriately }\end{array}$ & & & & & .738 & \\
\hline - Retention policy & & & & & & .795 \\
\hline - Job security & & & & & & .627 \\
\hline - Adequate leaves are given & & & & & & .614 \\
\hline
\end{tabular}

Source: Author calculation 
Table 2 explains several factors that contribute to the employee retention. Factor analysis was done using the direct oblimin rotation and finally six factors were formed to explain the employee retention criteria in the companies. Factors framed are as follows:

Factor 1 Work environment

$33.85 \%$ of the variations are explained by the work environment in the employee retention. The most factor under this is communication with the staff is easy followed by employees concerns are seriously considered. Suggestion of employees are considered, management decisions are unbiased, activities are done to de stress the employee, having great working relationship with colleagues and salary break up is satisfactory are the statements that combined in this factor. This clearly explains that if the employee feels connected with the company then there are more chances that employee would stay long with the company thus highlighting its good working environment.

Factor 2 Retention strategy

Learning and development opportunities are the most prominent statement in highlighting the retention strategy of the company. Total of $13 \%$ of variation in the employee retention is explained well by retention strategies followed by the company. This factor explained about the retention strategies of the companies by way of how career progression is possible, what rewards and other benefits company provide, did the company provide better working conditions and is there freedom while working.

Factor 3 Wages and compensation

$10.8 \%$ of total variation is explained with the most prominent being is yearly bonus given on time. Since wages and compensation is involved then having a fair and unbiased appraisal system is another important for the companies. Employee considers situations like extra payment given for overtime and incentives are given on the basis of performance.

Factor 4 Job satisfaction

Job satisfaction explains $8.7 \%$ of the variations and overall five statements formed this factor. Employees consider one job as the satisfying on only when there is adequate career development. This career development is followed by the work culture, salary, emotional attachment and company's image.

Factor 5 Welfare measures

Various companies take many kinds of welfare measures and the most prevalent among them is food offered at subsidised rates. Others are availability of first aid box, proper lunch breaks and other kings of break provided. All these explain about $7.1 \%$ of the variations.

Factor 6 Job security

Three statements are combined to form this factor explaining $4.329 \%$ variance. Job security as a retention strategy had the maximum factor score followed by 
job security as one of the factors that influences them to stay and the last adequate leaves are given.

\subsection{Factor analysis on the basis of gender (female)}

Table 3 shows several factors that contribute to the employee retention in case of female employees. Since the overall factors have been found earlier, this section highlights the shift in these factors as the gender of the employee changes. All the factors remained either same or few merged into one factor to explain the relevance of each in case of females and males.

Factor 1 Work environment

Nine statements were combined to form the first factor explaining $24.388 \%$ of variance. The maximum factor load was with statement lunch and other breaks are given appropriately. Statements like there are activities done to help employees de-stress, the suggestions given by employees are considered, employee concerns are seriously considered, salary breakup is satisfactory, have great working relationship with my colleagues, communication with the staff is easy and first aid box is available all the time are other factors that contribute to this factor and food is offered on subsidised rates.

Factor 2 Retention strategy

$19.901 \%$ variance is explained by the second factor combining five statements. Help in career progression is the statement with the maximum factor score. The other statements include reward and other benefits, freedom while working, working conditions, learning and development opportunities.

Factor 3 Brand image and career progression

Five statements were combined to form the third factor in which $15.531 \%$ of variance is explained. The work culture is the statement with maximum factor score. The others include career development, salary, job security and company's image.

Factor 4 Wages and compensation

Extra payment is given for overtime is the statement with maximum factor score. This is followed appraisal system is fair and unbiased, yearly bonus is given in time and performance based incentives are given. These four statements combined to form the fourth factor explaining $13.221 \%$ variance.

Factor 5 Job satisfaction

Three statements are combined, job security, adequate leaves are given and I am emotionally attached to my company to form the sixth factor, which has been renamed as job satisfaction accordingly. These factors explain around $8.22 \%$ of the reasons of job satisfaction among female employees. 
Table 3 Employee retention factors (female)

\begin{tabular}{|c|c|c|c|c|c|}
\hline Statements & 1 & 2 & 3 & 4 & 5 \\
\hline - Lunch breaks and other breaks are given appropriately & .945 & & & & \\
\hline - There are activities done to help employees de-stress. & .901 & & & & \\
\hline - The suggestions given by employees are considered & .791 & & & & \\
\hline - Employee concerns are seriously considered & .755 & & & & \\
\hline - Salary breakup is satisfactory & .666 & & & & \\
\hline - I have great working relationship with my colleagues & .646 & & & & \\
\hline - Communication with the staff is easy & .606 & & & & \\
\hline - First aid box is available all the time & .517 & & & & \\
\hline - Food is offered on subsidized rates & .794 & & & & \\
\hline - Help in career progression & & .976 & & & \\
\hline - Reward and other benefits & & .927 & & & \\
\hline - Freedom while working & & .751 & & & \\
\hline - Working conditions & & .736 & & & \\
\hline - Learning and development opportunities & & .725 & & & \\
\hline - Extra payment is given for overtime & & & .515 & & \\
\hline - Work culture & & & .920 & & \\
\hline - Career development & & & .918 & & \\
\hline - Salary & & & .867 & & \\
\hline - Job Security & & & .579 & & \\
\hline - Company’s image & & & .484 & & \\
\hline - The management decisions are unbiased & & & .432 & & \\
\hline - Appraisal system is fair and unbiased & & & & .915 & \\
\hline - Yearly bonus is given in time & & & & .739 & \\
\hline - Performance based incentives are given & & & & .550 & \\
\hline - Retention policy & & & & & .521 \\
\hline - Adequate leaves are given & & & & & .820 \\
\hline - I am emotionally attached to my company & & & & & .801 \\
\hline
\end{tabular}

Source: Author calculation

\subsection{Factor analysis on the basis of gender (male)}

Factor 1 Wages and compensation

Nine statements were combined to form the first factor. Salary was the statement with the maximum factor score. The others included yearly bonus is given on time, salary breakup is satisfactory, extra payment is given for overtime, appraisal system is fair and unbiased, employee concern are seriously considered, performance based incentives are given, the management decisions are unbiased and the work culture. Variance explained is $45.878 \%$. 
Table 4 Employee retention factors (male)

\begin{tabular}{|c|c|c|c|c|c|c|}
\hline Statements & 1 & 2 & 3 & 4 & 5 & 6 \\
\hline - Salary & .950 & & & & & \\
\hline - Yearly bonus is given in time & .948 & & & & & \\
\hline - Salary breakup is satisfactory & .888 & & & & & \\
\hline - Extra payment is given for overtime & .861 & & & & & \\
\hline - Appraisal system is fair and unbiased & .802 & & & & & \\
\hline - Employee concerns are seriously considered & .786 & & & & & \\
\hline - Performance based incentives are given & .719 & & & & & \\
\hline - The management decisions are unbiased & .607 & & & & & \\
\hline - Work culture & .442 & & & & & \\
\hline - Learning and development opportunities & & .868 & & & & \\
\hline - Freedom while working & & .724 & & & & \\
\hline - Help in career progression & & .512 & & & & \\
\hline - Reward and other benefits & & .483 & & & & \\
\hline - Food is offered on subsidized rates & & & .862 & & & \\
\hline - First aid box is available all the time & & & .768 & & & \\
\hline - Adequate leaves are given & & & .698 & & & \\
\hline $\begin{array}{l}\text { - Lunch breaks and other breaks are given } \\
\text { appropriately }\end{array}$ & & & .475 & & & \\
\hline - Job security & & & & .924 & & \\
\hline - Retention policy & & & & .680 & & \\
\hline - Working conditions & & & & .618 & & \\
\hline - I am emotionally attached to my company & & & & & -.769 & \\
\hline - Company's image & & & & & -.701 & \\
\hline - Career development & & & & & -.555 & \\
\hline $\begin{array}{l}\text { - I have great working relationship with my } \\
\text { colleagues }\end{array}$ & & & & & & .900 \\
\hline $\begin{array}{l}\text { - There are activities done to help employees } \\
\text { de-stress }\end{array}$ & & & & & & .647 \\
\hline $\begin{array}{l}\text { - The suggestions given by employees are } \\
\text { considered }\end{array}$ & & & & & & .466 \\
\hline - Communication with the staff is easy & & & & & & .458 \\
\hline
\end{tabular}

Source: Author calculation

Factor 2 Retention strategy

$14.911 \%$ variance is explained by the second factor combining four statements. Learning and development is the statement with the maximum factor score. The other statements include freedom while working, help in career progression, reward and other benefits. 


\section{Factor 3 Welfare measures}

Total variance explained here is $8.306 \%$. Four statements were combined to form the third factor. Food offered on subsidised rates was the statement with maximum factor score. The others include first aid box is available all the time, adequate leaves are given, lunch breaks and other breaks are given appropriately.

Factor 4 Job satisfaction

Three statements were combined to form the fourth factor explaining $6.384 \%$ of variance. The maximum factor load was with statement job security (in context of retention strategy). This was followed by Job security (in context of factors influencing most to stay in the organisation) and working conditions. The factor has been renamed job satisfaction.

Factor 5 Brand image and career progression

$6.132 \%$ variance is explained by the fifth factor combining three statements. The response on I am emotionally attached with the organisation, is the statement with the maximum factor score. The other statements include company's image and career development.

Factor 6 Work environment

Four statements were combined to form the sixth factor great working relationship with my colleagues was the statement with maximum factor score. The others include, there are activities done to help employees de-stress, the suggestions given by employees are considered and communication with the staff is easy. Variance explained is $4.499 \%$.

Table 5 Comparison of employee retention factors among females and males

\begin{tabular}{lcc}
\hline Factor no. & Female & Male \\
\hline 1 & Work environment & Wages and compensation \\
2 & Retention strategies & Retention strategies \\
3 & Brand image and career progression & Welfare measures \\
4 & Wages and compensation & Job satisfaction \\
5 & Job satisfaction & Brand image and career progression \\
6 & & Work environment \\
\hline
\end{tabular}

Source: Author representation

After observing Table 5, it can be summarised that the most important factor in case of female staff retention is work environment (includes proper breaks, de stressing environment, among others) the second is retention strategies and the third factor is brand image and career progression. The male staff looks for good wages and compensation (includes salary, yearly bonus, among others) the second most important factor for male staff is retention strategies and the third is welfare measures. 


\subsection{Factors for employee retention on the basis of age (20-30 years)}

Table 6 shows several factors contribute to the employee retention in case of employees falling in the age group of 20-30 yrs. In the end all the statements are merged into six major factors. Table 6 shows these factor details.

Factor 1 Welfare measures

Five statements were combined to form the first factor explaining 33.885\%of variance. The maximum factor load was with lunch breaks and other breaks are given on time. This was followed by food is offered on subsidised rates, I have great working relationship with my colleagues, first aid box is available all the time and there are activities done to help employees de-stress.

Factor 2 Retention strategy

$19.648 \%$ variance is explained by the second factor combining five statements. Learning and development opportunities have the maximum factor score. The other statements include freedom while working, working conditions, help in career progression and reward and other benefits.

Factor 3 Brand image and career progression

Four statements were combined to form the third factor to explain $12.429 \%$ of variance. Salary was the statement with maximum factor score. The others include work culture, career development job security and yearly bonus is given in time.

Factor 4 Wages and compensation

Five statements were combined to form the fourth factor explaining $9.958 \%$ of variance. The maximum factor load was with statement salary break up is satisfactory. This was followed by employee concerns are seriously considered, performance based incentives are given, appraisal system is fair and unbiased and the management decisions are unbiased.

Factor 5 Job satisfaction

$6.696 \%$ variance is explained by the fifth factor combining four statements. Job security two times is the statement with the more factor score. The others are adequate leaves are given and company's image. The factor is given this name accordingly.

Factor 6 Work environment

Four statements were combined to form the sixth factor explaining $4.125 \%$ of variance. Extra payment is given for overtime was the statement with maximum factor score. The others include, communication with the staff is easy I am emotionally attached to my company and the suggestions given by employees are considered. 
Table 6 Factor analysis on the basis of age (20-30 years)

\begin{tabular}{|c|c|c|c|c|c|c|}
\hline Statements & 1 & 2 & 3 & 4 & 5 & 6 \\
\hline $\begin{array}{l}\text { - Lunch breaks and other breaks are given } \\
\text { appropriately. }\end{array}$ & .873 & & & & & \\
\hline - Food is offered on subsidized rates & .793 & & & & & \\
\hline $\begin{array}{l}\text { - I have great working relationship with my } \\
\text { colleagues }\end{array}$ & .780 & & & & & \\
\hline - First aid box is available all the time & .759 & & & & & \\
\hline $\begin{array}{l}\text { - There are activities done to help employees } \\
\text { de-stress }\end{array}$ & .710 & & & & & \\
\hline - Learning and development opportunities & & .925 & & & & \\
\hline - Freedom while working & & .903 & & & & \\
\hline - Working conditions & & .872 & & & & \\
\hline - Help in career progression & & .808 & & & & \\
\hline - Reward and other benefits & & .741 & & & & \\
\hline - Salary & & & .929 & & & \\
\hline - Work culture & & & .859 & & & \\
\hline - Career development & & & .815 & & & \\
\hline - Yearly Bonus is given in time & & & .658 & & & \\
\hline - Salary breakup is satisfactory & & & & .825 & & \\
\hline - Employee concerns are seriously considered & & & & .801 & & \\
\hline - Performance based incentives are given & & & & .661 & & \\
\hline - Appraisal system is fair and unbiased & & & & .535 & & \\
\hline - The management decisions are unbiased & & & & .489 & & \\
\hline - Retention policy & & & & & .767 & \\
\hline - Job security & & & & & .656 & \\
\hline - Adequate leaves are given & & & & & .630 & \\
\hline - Company’s image & & & & & .626 & \\
\hline - Extra payment is given for overtime & & & & & & .449 \\
\hline - Communication with the staff is easy & & & & & & .790 \\
\hline - I am emotionally attached to my company & & & & & & .680 \\
\hline $\begin{array}{l}\text { - The suggestions given by employees are } \\
\text { considered }\end{array}$ & & & & & & .510 \\
\hline
\end{tabular}

Source: Author calculation

\subsection{Factors for employee retention on the basis of age (30-40 years)}

Table 7 shows several factors that contribute to the employee retention in case of employees falling in the age group of 30-40 yrs. Relevance of the factors changes as the age of the respondent changes from 20-30 years. 
Table 7 Factor analysis on the basis of age (30-40 years)

\begin{tabular}{|c|c|c|c|c|c|c|}
\hline Statements & 1 & 2 & 3 & 4 & 5 & 6 \\
\hline $\begin{array}{l}\text { - The suggestions given by employees are } \\
\text { considered }\end{array}$ & .818 & & & & & \\
\hline - The management decisions are unbiased & .759 & & & & & \\
\hline $\begin{array}{l}\text { - There are activities done to help employees } \\
\text { de-stress }\end{array}$ & .713 & & & & & \\
\hline $\begin{array}{l}\text { - I have great working relationship with my } \\
\text { colleagues }\end{array}$ & .616 & & & & & \\
\hline - Communication with the staff is easy & .456 & & & & & \\
\hline - Company's image & & .427 & & & & \\
\hline - I am emotionally attached to my company & & -.828 & & & & \\
\hline - Career development & & -.630 & & & & \\
\hline - Freedom while working & & -.497 & & & & \\
\hline - Extra payment is given for overtime & & & -.901 & & & \\
\hline - Job security & & & -.744 & & & \\
\hline $\begin{array}{l}\text { - Lunch breaks and other breaks are given } \\
\text { appropriately. }\end{array}$ & & & .551 & & & \\
\hline - Performance based incentives are given & & & -.536 & & & \\
\hline - Food is offered on subsidized rates & & & & .941 & & \\
\hline - First aid box is available all the time & & & & .512 & & \\
\hline - Adequate leaves are given & & & & & .784 & \\
\hline - Work culture & & & & & .780 & \\
\hline - Working conditions & & & & & .725 & \\
\hline - Job security & & & & & .706 & \\
\hline - Appraisal system is fair and unbiased & & & & & & .438 \\
\hline - Reward and other benefits & & & & & & .829 \\
\hline - Salary breakup is satisfactory & & & & & & .794 \\
\hline - Salary & & & & & & .690 \\
\hline - Yearly bonus is given in time & & & & & & .646 \\
\hline - Help in career progression & & & & & & .474 \\
\hline - Learning and development & & & & & & -.981 \\
\hline
\end{tabular}

Source: Author calculation

Factor 1 Work environment

Five statements were combined to form the first factor explaining $36.991 \%$ of variance. The maximum factor load was with suggestions given by the staff are considered. This was followed by the management decisions are unbiased, there are activities done to help employees de-stress and great working relationship with my colleagues and communication with the staff is easy. 
Factor 2 Brand image and career progression

$23.088 \%$ variance is explained by the second factor combining four statements. Company's image being the first followed by I am emotionally attached with my organisation, career development and freedom while working.

Factor 3 Wages and compensation

Four statements were combined to form the third factor that explains $9.735 \%$ of variance. Extra pay is given for overtime was the statement with maximum factor score. The others include job security, lunch breaks and other breaks are given appropriately, performance based incentives are given.

Factor 4 Welfare measures

$5.330 \%$ variance is explained by the fourth factor combining two statements. The maximum factor score was with statement food is offered on subsidised rates followed by first aid box is available.

Factor 5 Job satisfaction

Four statements were combined to form the fifth factor explaining $4.754 \%$ of variance. Adequate leaves given were the most important factor. The others include, work culture, working conditions and job security.

Factor 6 Retention strategy

Seven statements were combined to form this factor that explains $47.836 \%$ of variance. The maximum factor score was with statement appraisal system is fair and unbiased. This was followed by rewards and other benefits, salary break up is satisfactory, salary, yearly bonus is given on time, help in career progression and learning and development.

Table 8 Comparison of employee retention factors among organization level (20-30 yrs) and (30-40 yrs)

\begin{tabular}{lcc}
\hline Factor no. & $20-30$ yrs & $30-40$ yrs \\
\hline 1 & Welfare measures & Work environment \\
2 & Retention strategies & Brand image and career progression \\
3 & Brand image and career progression & Wages and compensation \\
4 & Wages and compensation & Welfare measures \\
5 & Job satisfaction & Job satisfaction \\
6 & Work environment & Retention strategies \\
\hline
\end{tabular}

Table 8 shows the most important factor for employees between 20-30 yrs. of age are welfare measures (it includes proper breaks between works, subsidised food, among others). The second and third most important factors are retention strategies and brand and career progression. In case of the employees between 30-40 yrs of age the most important factor is great work environment(this includes their suggestions getting considered, unbiased management decision, among others) the second and third most important factors are brand image and career progression, wages and compensation. 


\subsection{Employee retention factors on the basis of organisational level (middle level)}

Table 9 shows several factors that contribute to the employee retention in case of employees falling in the middle level organisational level.

Factor 1 Work environment

Eight statements were combined to form the first factor explaining $27.804 \%$ of variance. The maximum factor load was with communication with the staff is easy. This was followed by Suggestions given by the staff are considered, employee concerns are seriously considered, management decisions are unbiased, activities are done to help the employees de stress, salary breakup is satisfactory, performance based incentives are given and great work relationship with the colleagues.

Factor 2 Retention strategy

$16.857 \%$ variance is explained by the second factor combining three statements. Reward and other benefits was the statement with maximum factor score. The other statements include learning and development opportunities and help in career progression.

Factor 3 Wages and compensation

Three statements were combined to form the third factor explaining $12.544 \%$. Extra payment is given for overtime was the statement with maximum factor score. The others include appraisal system is fair and unbiased and freedom while working.

Factor 4 Job satisfaction

$10.583 \%$ variance is explained by the fourth factor combining three statements. The maximum factor score was with statement job security. This was followed by company's image and working conditions. The factor is renamed job satisfaction accordingly.

Factor 5 Welfare measures

Four statements were combined to form the fifth factor that explains $6.397 \%$ of variance. Food is offered on subsidised rates was the statement with maximum factor score. The others include first aid box is available all the time lunch breaks and other breaks are given appropriately and adequate leaves are given.

Factor 6 Brand image and career progression

$4.572 \%$ variance is explained by the sixth factor combining five statements. The maximum factor score was with statement yearly bonus is given on time, this was followed by work culture, career development, salary, I am emotionally attached with my organisation and yearly bonus is given on time. 
Table 9 Employee retention factors on the basis of organization level (middle level)

\begin{tabular}{|c|c|c|c|c|c|c|}
\hline Statements & 1 & 2 & 3 & 4 & 5 & 6 \\
\hline - Communication with the staff is easy & .941 & & & & & \\
\hline $\begin{array}{l}\text { - The suggestions given by employees are } \\
\text { considered }\end{array}$ & .900 & & & & & \\
\hline - Employee concerns are seriously considered & .863 & & & & & \\
\hline - The management decisions are unbiased & .693 & & & & & \\
\hline $\begin{array}{l}\text { - There are activities done to help employees } \\
\text { de-stress }\end{array}$ & .650 & & & & & \\
\hline - Salary breakup is satisfactory & .622 & & & & & \\
\hline - Performance based incentives are given & .596 & & & & & \\
\hline $\begin{array}{l}\text { - I have great working relationship with my } \\
\text { colleagues }\end{array}$ & .564 & & & & & \\
\hline - Reward and other benefits & & .844 & & & & \\
\hline - Learning and development opportunities & & .679 & & & & \\
\hline - Help in career progression & & .663 & & & & \\
\hline - Extra payment is given for overtime & & & -.785 & & & \\
\hline - Appraisal system is fair and unbiased & & & -.756 & & & \\
\hline - Freedom while working & & & .701 & & & \\
\hline - Job security & & & & .887 & & \\
\hline - Company's image & & & & .742 & & \\
\hline - Working conditions & & & & .594 & & \\
\hline - Food is offered on subsidized rates & & & & & .908 & \\
\hline - First aid box is available all the time & & & & & .819 & \\
\hline $\begin{array}{l}\text { - Lunch breaks and other breaks are given } \\
\text { appropriately }\end{array}$ & & & & & .719 & \\
\hline - Adequate leaves are given & & & & & .674 & \\
\hline - Yearly bonus is given in time & & & & & & .403 \\
\hline - Work culture & & & & & & .891 \\
\hline - Career development & & & & & & .790 \\
\hline - Salary & & & & & & .698 \\
\hline - I am emotionally attached to my company & & & & & & .481 \\
\hline
\end{tabular}
Source: Author calculation

\subsection{Employee retention factors on the basis of organisational level (senior level)}

Table 10 shows several factors that contribute to the employee retention in case of employees falling in the category of senior level staff. 
Table 10 Employee retention factors on the basis of organizational level (senior level)

\begin{tabular}{|c|c|c|c|}
\hline Statements & 1 & 2 & 3 \\
\hline Company's image & 1.117 & & \\
\hline Salary & 1.117 & & \\
\hline Freedom while working & .955 & & \\
\hline Lunch breaks and other breaks are given appropriately & .955 & & \\
\hline Working conditions & .894 & & \\
\hline The suggestions given by employees are considered & .894 & & \\
\hline Career development & .870 & & \\
\hline Learning and development opportunities & .870 & & \\
\hline Work culture & .727 & & \\
\hline I am emotionally attached to my company & .717 & & \\
\hline I have great working relationship with my colleagues & .657 & & \\
\hline Salary breakup is satisfactory & .657 & & \\
\hline Help in career progression & .529 & & \\
\hline Appraisal system is fair and unbiased & .529 & & \\
\hline Job security & .529 & & \\
\hline Communication with the staff is easy & .529 & & \\
\hline First aid box is available all the time & .529 & & \\
\hline Yearly bonus is given in time & & -1.03 & \\
\hline Food is offered on subsidized rates & & .882 & \\
\hline Employee concerns are seriously considered & & & .460 \\
\hline Adequate leaves are given & & & 1.030 \\
\hline Extra payment is given for overtime & & & 1.030 \\
\hline There are activities done to help employees de-stress & & & .916 \\
\hline Reward and other benefits & & & .815 \\
\hline The management decisions are unbiased & & & .726 \\
\hline Job security & & & .726 \\
\hline Performance based incentives are given & & & .510 \\
\hline
\end{tabular}

Source: Author calculation

Factor 1 Brand image and career progression

Seventeen statements were combined to form the first factor explaining $79.749 \%$ of variance. The maximum factor load was with company's image. This was followed by salary, freedom while working, lunch breaks and other breaks are given appropriately, working conditions, the suggestions given by employees are considered, career development, learning and development opportunities, work culture, emotional attachment with company, I have great 
working relationship with my colleagues, salary breakup is satisfactory, help in career progression, appraisal system is fair and unbiased, communication with the staff is easy and first aid box is available all the time.

Factor 2 Welfare measures

$11.354 \%$ variance is explained by the second factor combining two statements. With yearly bonus is given on time being the statement with more factor score. The other statements include food is offered on subsidised rates

Factor 3 Job satisfaction

$8.897 \%$ variance is explained by the third factor combining eight statements. The maximum factor score was with employee concerns are seriously considered statement adequate leaves are given. This was followed by extra payment is given for overtime, there are activities done to help employees de-stress, reward and other benefits, the management decisions are unbiased, job security and performance based incentives are given. The factor is named job satisfaction accordingly.

Table 11 shows that for middle level staffs the most important factor is work environment. (This factor includes easy communication with staff, suggestions considered by management, among others). The second and third most important factors are retention strategies and wages and compensation. The senior level staffs considers brand image and career progression the most important factor for retention, the second and third most important factors for them are welfare measures and job satisfaction

Table 11 Comparison of employee retention factors for middle and senior level

\begin{tabular}{lcc}
\hline Factor no. & Middle level & Senior level \\
\hline 1 & Work environment & Brand image and career progression \\
2 & Retention strategies & Welfare measures \\
3 & Wages and compensation & Job satisfaction \\
4 & Job satisfaction & \\
5 & Welfare measures & \\
6 & Brand image and career progression & \\
\hline
\end{tabular}

Source: Author representation

\section{Implications}

The findings from this study are very useful for the management and the HR departments of all the organisations who are facing the problem of staff turnover. The present study has useful practical implications as it clearly mentions the major reasons behind employee turnover. All employees have certain expectations from the employer. If these expectations are met the staffs are retained else there is a problem of staff turnover. There is an emphasis on certain factors that can help the companies retain its top talent. Since the results are based on three parameters, i.e., age, gender and organisational level of the employee, the study can assist the employers handle the retention issues more effectively. The factors discussed in the study if considered seriously will help the employers reap 
benefits of their most talented employees which would eventually lead to successful business. Most of the employers today realise that to build a successful company they need longevity of the staff. Thus present study will be of great help to the employers who want a staff that can help the company reach its long term goals.

\section{Limitations}

This empirical research was done to determine the predominant factors that influence an employee to leave his organisation and join another one. It also aimed to study the reasons behind employee turnover based on gender, age and organisation level. The ultimate objective was to suggest the strategies that can help organisations retain its employees for a longest possible time. Although the research carried out was theoretically and empirically sound, like any other research, this also had certain limitations that could impact the findings of this study, such as:

- The study was based on a specific sample size in a specific location, so there is a possibility that it suffers certain limitations. The results may have been more generalisable if a bigger sample had been taken.

- The respondents may not have given true answers reflecting their actual feelings while responding to the questionnaire, as they may not be comfortable to talk about their dissatisfaction (if any) with the current job, or relationship with the colleagues, problems with working environment, lack of growth opportunities, or dissatisfaction with the salary among others.

\section{Future research directions}

Based on the study, the following directions for future research may be considered.

- In addition to Delhi/NCR the other geographical areas could be included to extend the study and to have broader results.

- This study is based on analysis which was carried out with a questionnaire using a likert-type scale. However In future, it can be supplemented with an in-depth interview to gather qualitative or descriptive responses from participants.

- This research was conceptualised based on review of existing literature on this topic. Receiving more inputs from top management may have provided very useful vital inputs.

- Additional research could consider other parameters like dependence of other family members on the income of the respondent, their marital status among others.

\section{Conclusions}

Employees are the most important and valuable asset of the company. The analyses and findings clearly prove that the organisations must focus on keeping the staff happy and 
satisfied. By seeing the results it can easily be said that the good retention strategies adopted by companies definitely help in reducing employee turnover. Employees who are talented and motivated keep high expectation from the companies. It is however not difficult to satisfy such staff members. Employees in general want to be pushed so that they perform better; they wish to be motivated by the environment at the work place. The employees also always look for personal and professional growth opportunities. It is now more important than ever for organisations to have satisfied and productive employees. When they are dedicated and involved completely in the company, profits are automatically higher. Similarly the company is bound to suffer when the employees are dissatisfied. Companies today need to focus on its employees and support them not only in difficult times at work but also in any kind of personal problems. The employees want to feel important so employers need to recognise and appreciate their work. Valuable feedback provided to employees can also make them feel valued to the organisation and make them more responsible and confident. An environment of trust at the workplace helps the employees stick to the job for a longer time. Thus the companies must ensure that they are keeping the top talent of the organisation happy and content which is extremely vital for the growth of the company.

\section{References}

Bagga, G. (2013) 'How to keep the talent you have got', Human Resource Management International Digest, Vol. 21, No. 1, pp.3-4.

Dana, L.P. (2000) 'Creating entrepreneurs in India', Journal of Small Business Management, Vol. 38, No. 1, pp.86-91.

Das, B.L. and Baruah, M. (2013) 'Employee retention: a review of literature', IOSR Journal of Business \& Management, Vol. 14, No. 2, pp.8-16.

Dutta, A. and Banerjee, S. (2014) 'Study of employee retention', International Journal of Business Management and Research, Vol. 4, No. 1, pp.83-88.

Edwards, A. (2015) Five Reasons to Retain Employees [online] http://blog.datis.com/2015/04/22 /5-reasons-to-retain-employees/ (accessed 22 April).

Irshad, M. (2011) 'Factors affecting employee retentio: evidence from litreture review', Abasyn University Journal of Social Sciences, Vol. 4, No. 1, pp.84-102.

Kossivi, B., Xu, M. and Kalgora, B. (2016) 'Study on determining factors of employee retention', Open Journal of Social Sciences, Vol. 4, No. 5, pp.261-268.

Kyndt, E., Dochy, F. and Baert, H. (2011) 'Influence of learning and working climate on the retention of talneted employees', Journal of Workplace Learning, Vol. 23, No. 1, pp.35-55.

Mehta, M., Kurbetti, A. and Dhankar, R. (2014) 'Study on employee retention and attrition', International Journal of Advance Research in Computer Science and Management Studies, Vol. 4, No. 5, pp.154-63.

Merhar, C. (2016) Employee Retention: The Real Cost Of Losing An Employee [online] https://www.zanebenefits.com/blog/bid/312123/employee-retention-the-real-cost-of-losing-anemployee (accessed 4 February).

Mohlala, J., Goldman, G.A. and Goosen, X. (2012) 'Employee retention within the information technology division of a South African bank', SA Journal of Human Resource Management, Vol. 4, No. 3, pp.438-449.

Nazia, S. and Begum, B. (2013) 'Employee retention practices In Indian corporate-a study of select MNC's', International Journal of Engineering and Management Sciences, Vol. 5, Nos. 1/2, pp.361-368. 
Ramlall, S. (2004) 'A review of employee motivation theories and their implications for employee retention within the organization', Journal of American Academy of Business, pp.52-63.

Sageer, A., Rafat, S. and Agarwal, P. (2012) 'Identification of the variables affecting employee satisfaction', IOSR Journal of Business and Management (IOSR-JBM), Vol. 5, No. 1, pp.32-39.

Samuel, M.O. and Chipunza, C. (2009) 'Employee retention and turnover using motivational variables as a Panacea', African Journal of Business Management, Vol.3, No. 8, pp.410-415.

Satpal and Dhillon, M. (2016) 'Retaining employees in Indian IT sector', International Journal of Science Technology and Management, Vol. 5, No. 3, pp.163-168.

Savarimuthu, H. (2013) 'A study on employee retention techniques', Journal of Business Management \& Social Science \& Research, Vol. 2, No. 8, pp.45-49.

Shakeel, N. and Butt, S. (2015) 'Factors influencing employee retention: an integrated perspective', Journal of Resources Development Management, Vol. 6, No. 1, pp.32-49.

Siddiqui, F. (2015) Importance of Employee Retention in Business Organization [online] https://www.linkedin.com/pulse/importance-employee-retention-business-organization-fareed (accessed 4 April).

Sinha, C. and Sinha, R. (2012) 'Factors affecting employee retention: a comparative analyses of two organizations from heavy engineering industry', European Journal of Business and Management, Vol. 4, No. 3, pp.145-162.

Son, S. (2016) Importance of Employee Retention, Explained 8 Ways [online] https://www.tinypulse.com/blog/importance-of-employee-retention (accessed 1 December). 